\title{
SECOND LANGUAGE ACQUISITION AS A CLASH OF CONSCIOUSNESS
}

\author{
Mark A. Clarke \\ University of Michigan
}

\begin{abstract}
Recent interest in "humanism" in second language teaching and learning has produced a number of interesting paradigms for the examination of psycho-sociological factors in second language learning. Of particular note are the theoretical perspectives developed by Guiora et al. (1972, 1975), Gardner and Lambert (1972), and Schumann (1976). These characterizations of second language learning do not, however, provide explanations which lead directly to the identification and solution of problems faced by students in a foreign culture. This paper presents a theoretical perspective of second language learning which explains cross cultural problems in terms of conflicting definitions of reality. First, parallels are drawn between the trauma endured by ESL students in the United States and that endured by schizophrenics. Then, culture and language shock are discussed in terms of the conflicts experienced by individuals from traditional societies as they attempt to adjust to a "modernized" society.
\end{abstract}

The problems faced by newcomers to a culture have always been a concern of second language teachers, but increased interest in "humanistic" teaching and learning (See, for example, Brown 1975, Grittner 1973) has made the issue of cultural adjustment a primary focus for second language researchers and teachers.

A number of researchers have argued that second language learning involves a fundamentally traumatic experience for the individual. Guiora and his colleagues at the University of Michigan (Guiora et al. 1972, 1975) have studied personality factors in an attempt to account for difficulties encountered by second language learners. In addition, the myriad projects of researchers at McGill University (among many, see Gardner and Lambert 1972, Gardner 1973) have provided powerful evidence for the position that learner attitudes toward the target culture and motivation to learn determine success in second language learning. Recently, Schumann (1976) developed the notion of distance between social groups to explore the ways in which social factors influence the degree of success experienced by second language learners. 
As useful as these studies have been, they do not provide teachers with information that can serve as the foundation for interpersonal interaction in the classroom; the theories on which they are based are descriptive, not predictive. It is interesting but not extremely useful to know that a particular student "suffers from a sense of shame..." because he cannot "...tolerate the infantile situation..." of learning a new language (Stengel 1939:476), or that integrative motivation (the desire to become part of a group) is more characteristic of good language learners than instrumental motivation (the desire to learn a language to get a job, or to improve one's status in a present job) (Taylor 1973:145); or that the perceived status of one language group in relationship to another affects the individual's degree of success in second language learning (Schumann 1976:136). There is, after all, little that we language teachers can do to affect a student's self-image, his desire to become a part of the target culture, or his perception of the relative status of his society to ours. Awareness of these issues certainly makes us more sensitive and effective teachers, but such awareness does not put us in a position to help students understand or solve their learning problems. It is hoped that the theoretical perspective of second language learning presented here will remedy this weakness.

A primary contention of this paper is that students' difficulties in learning a second language often stem, not so much from their inability to handle stressful situations, nor from their negative attitudes or lack of motivation, but rather, from their lack of understanding of the social context of the language. It is impossible for language teachers to attempt to become familiar with the culture and customs of every student in a class, especially when twenty students might represent as many as twelve to fifteen different countries. However, an understanding of "modern consciousness" as outlined by phenomenologists (see Berger and Luckmann 1967, Berger, Berger and Kellner 1973) provides teachers with a valuable tool for explaining social phenomena to students.

In the pages which follow, I describe a theoretical framework which can be used by language teachers to predict sources of confusion for ESL students studying in the United States. In the first part of the article I characterize the psychological and social stresses of second language learning as being similar to those suffered by victims of schizophrenia. In the second part I discuss culture and language shock in terms of a clash of consciousness; students' inability to learn a second language and their difficulties 
in the culture are seen as resulting from fundamental differences in definitions of reality.

\section{Second language learning as schizophrenia}

It can be argued that language learning involves an essentially inescapable element of the "double bind." As elaborated by Bateson (1972), a double bind exists in situations where an individual will be "punished" if he does one thing, or another thing, or nothing at all. The Zen master's attempts to lead his students to enlightenment serve as an example: "One of the things he does is to hold a stick over the pupil's head and say fiercely, 'If you say this stick is real, I will strike you with it. If you say the stick is not real I will strike you with it. If you don't say anything I will strike you with it." (Bateson 1972:208) Bateson points out that the Zen student has the option of reaching up and taking the stick, an option which is not open to individuals who feel that, no matter what they do in a social relationship, they will be punished. For example, for foreign students in the United States, where there exists a notorious lack of concern for non-English speakers, it often appears that their best efforts not only fail to accomplish their objectives, but also result in embarrassing and painful rebukes from the people they are in contact with.

Bateson's objective is to develop a theory of schizophrenia which demonstrates that unexplained, seemingly irrational behavior can often be understood if one looks at the total context of the behavior. As Laing $(1967: 114,115)$ puts it:

\footnotetext{
...to the best of our knowledge, no schizophrenic has been studied whose disturbed pattern of communication has not been shown to be a reflection of, and reaction to, the disturbed and disturbing pattern characterizing his or her family of origin .... it seems to us that without exception the experience and behavior that gets labeled schizophrenic is a special strategy that a person invents in order to live in an unliveable situation.
}

The concept of an environmentally induced schizophrenia has a great deal to offer second language researchers and teachers. The parallels between schizophrenia-inducing environments and the situation encountered by visitors to a strange culture are striking.

Oberg (1960) discusses the problems faced by people who have been suddenly transplanted abroad. Like the schizophrenic, the foreigner suffers from a sense of helplessness in the face of confusing and conflicting environmental cues: 
Culture shock is precipitated by the anxiety that results from losing all our familiar signs and symbols of social intercourse ... these cues, which may be words, gestures, facial expressions, customs or norms, are acquired by all of us in the course of growing up and are as much a part of our culture as the language we speak or the beliefs we accept. (Oberg 1960:177).

Individuals in a strange environment are in a constant state of tension, described by Howard and Scott (1965) as a necessary precursor to action aimed at solving a problem; if however, the problem is not solved, the difficulties experienced by the individual are compounded by the unresolved tension. The individual finds himself in a continuous state of double bind. Bateson (1972:208) summarizes the characteristics of the double bind situation:

1. ...the individual is involved in an intense relationship; that is, a relationship in which he feels it is vitally important that he discriminate accurately what sort of message is being communicated so that he may respond appropriately.

2 . ..the individual is caught in a situation in which the other person in the relationship is expressing two orders of message and one of these denies the other.

3. ...the individual is unable to comment on the messages being expressed to correct his discrimination of what order of message to respond to, ie., he cannot make a metacommunicative statement.

Students of a foreign language, especially in the culture of the target language, at one time or another suffer from all three of the above conditions. Virtually every encounter with people from that culture becomes an "intensive relationship" by virtue of the fact that extreme effort is necessary to keep communication from breaking down. Getting a taxi driver to understand where you want to go; attempting to discover if he has indeed understood you, given that he says he has, but continues to drive in the wrong direction; and searching frantically all the while for the proper phrases to express yourself so that you don't appear stupid or patronizing; all of this combines to give a simple ride across town Kafkaesque proportions which cannot be easily put in perspective by the person who has suffered through them.

For the individual in a strange culture, social encounters become inherently threatening, and defense mechanisms are employed to reduce the trauma. Here again, the similarities between the schizophrenic and a person in a foreign environment are striking. Bateson (1972:211) describes the alternatives commonly adopted by a schizophrenic to defend himself:

1. He might... assume that behind every statement there is a concealed meaning which is detrimental to his welfare.... If he chooses this alternative, he will be continually searching for 
meanings behind what people say and behind chance occurrences in the environment, and he will be characteristically suspicious and defiant.

2. He might ... tend to accept literally everything people say to him; when their tone or gesture or context contradicted what they said he might establish a pattern of laughing off these metacommunicative signals.

3. If he didn't become suspicious of metacommunicative messages or attempt to laugh them off, he might choose to ignore them. Then he would find it necessary to see and hear less and less of what went on around him, and do his utmost to avoid provoking a response in his environment.

The behaviors described above are examples of ways to react to situations in which one does not understand the rules of social interaction. Schizophrenics develop patterns of behavior and communication which help them navigate their way through a complex and threatening reality. Such solutions to problems, while causing individuals to be labeled insane and perhaps institutionalized, are essential, balance-restoring mechanisms which allow one to make sense of the world. A second language learner may escape the institutional sanctions imposed on the schizophrenic, but the trauma of interaction with people from another culture can be just as painful as the day-to-day existence of the schizophrenic.

Oberg's (1960:178) description of the behavior of sufferers of culture shock is familiar to anyone who has lived abroad:

Some of the symptoms of culture shock are: excessive washing of the hands; excessive concern over drinking water, food, dishes and bedding; fear of physical contact with attendants or servants; the absent-minded, far-away stare; a feeling of helplessness and a desire for dependence on long-term residents of one's own nationality, fits of anger over delays and other minor frustrations; excessive fear of being cheated, robbed, or injured. ...

People exhibiting the above behaviors would run the risk of being labeled mentally incompetent if their actions were examined out of context. Although bizarre, they are at least understandable when seen as defense mechanisms used by an individual in a strange environment. Oberg goes on to give examples of the types of reactions commonly used by sufferers of culture shock to mitigate their frustrations. Often, they reject the new environment, retreating into comfortable enclaves of fellow-sufferers. A great deal of time and effort is then spent in avoiding contact with the "locals" and such encounters that do occur are characterized by extreme suspicion and hostility. When they are forced to interact with nationals, there is a tendency to attend to the literal meaning of words or to refuse to study non-linguistic communication which might clarify the messages being transmitted. 
The above sketch of environmentally-induced schizophrenia provides a framework for a description of the experiences and reactions of second language learners, but an explanation of the reasons for the special trauma of second language learning must be based in cross-cultural studies. In the following section, tenets from phenomenology are used for such an examination.

\section{Clash of consciousness}

Howard and Scott (1965:141) have developed a framework for the analysis of stress which characterizes the nature of problems encountered by people attempting to live in a strange culture: "Viewing human functioning as a problem-solving phenomenon, stress is here explained in terms of tension that results from the organism's inability to master presenting problems, and its consequent need to devote excess energy to maintenance activities."

For the majority of people functioning in their own environment, day-to-day maintenance activities are accomplished with little or no conscious effort. In a foreign culture, however, every event or social encounter becomes potentially problematic.

The exact nature of a person's problems depends, of course, on a number of variables, including one's personality characteristics, previous experience in foreign countries, the nature of interpersonal encounters with members of the target culture, and the degree of difference between one's own culture and the host culture. It is obvious that we second language teachers cannot possibly organize our classes as group therapy sessions which adequately explore each student's particular problems en route to psychological health and mastery of the target language. It is possible, however, to examine second language learning as a clash of consciousness, in which double bind phenomena are viewed as the result of differences between culturally determined definitions of reality.

It is my contention that the most serious difficulties encountered by foreign students in the U.S. occur as a result of the differences between their country and the U.S. in terms of "modernity." Furthermore, I believe that a theory of second language teaching based on a description of modern consciousness will provide teachers with a comprehensive framework within which isolated events can be understood and dealt with.

My argument will follow closely that put forth by students of phenomenology and sociology of knowledge, notably Berger and 
Luckmann (1967) and Berger, Berger, and Kellner (1973). Berger et $a l$. , (1973) stress that "modern" in this context carries no value connotation, indeed, that there are as many negative connotations of the term as there are positive ones. Modernization is viewed in close relationship to economic growth, especially that which occurs as a result of technological advancement. They discuss modernization as "the institutional concomitants of technologically induced economic growth. This means that there is no such thing as a "modern society" plain and simple; there are only societies more or less advanced in a continuum of modernization." (Berger et al. 1973:9) When individuals come to the U.S. from their own cultures, they will need to make a number of important psychological adjustments; how many and how great the adjustments depend on the degree of difference in modernization between their society and the U.S.

In this perspective, the individual is seen as an imperfect reflection of society, whose self has developed through an interaction with the cultural environment. G. H. Mead (1964:33) comments:

\begin{abstract}
...the human self arises through its ability to take the attitude of the group to which he belongs-because he can talk to himself in terms of the community to which he belongs and lay upon himself the responsibilities that belong to the community; because he can recognize his own duties as against others - that is what constitutes the self as such.... The structure of society lies in these social habits, and only insofar as we can take these social habits into ourselves can we become selves.
\end{abstract}

Berger and Luckmann (1967:50) stress that the self cannot be viewed in isolation from the individual's social experiences:

The genetic presuppositions for the self are, of course, given at birth. But the self, as it is experienced later as a subjectively and objectively recognizable identity, is not. The same social processes that determine the completion of the organism produce the self in its particular, culturally relative form. The character of the self as a social product is not limited to the particular configuration the individual identifies as himself (for instance, as a "man" in the particular way in which this identity is defined and formed in the culture in question), but to the comprehensive psychological equipment that serves as an appendage to the particular configuration (for instance, "manly" emotions, attitudes and even somatic reactions). It goes without saying, then, that ... the self cannot be adequately understood apart from the particular social context in which it was shaped.

An essential aspect of the self is one's consciousness, the organized pattern of meanings which individuals depend upon to guide them through encounters with the environment. Consciousness, of 
course, develops in a social context, and phenomenologists give primary importance to the reality of everyday life as a powerful force in the development of one's consciousness. Berger and Luckmann (1967:21-23) outline the important characteristics of everyday reality:

1. The reality of everyday life is seen as paramount reality. The tension of consciousness is highest in everyday life.... It is impossible to ignore, difficult even to weaken in its imperative presence.

2. The reality of everyday life is apprehended as an ordered reality. Its phenomena are prearranged in patterns that seem to be independent of one's apprehension of them.

3 . The reality of everyday life is organized around the here of one's body and the now of the present... . This means that one experiences everyday life in terms of differing degrees of closeness and remoteness both spatially and temporally.

4. The reality of everyday life is perceived as an intersubjective world, a world that is shared with others. One is confident that there is an ongoing correspondence between one's meanings and others' meanings.

5. The reality of everyday life is taken for granted as reality. While one is capable of engaging in doubt about its reality, one is obliged to suspend such doubt during the routine of everyday life.

One's consciousness is inextricably bound up in the unconscious network of ideas, opinions, and presuppositions that one brings to any social encounter. For most people, this reality is never questioned nor even, perhaps, recognized as potentially different from reality as perceived by others. Foreign students in the U.S., of course, are forced to confront a different reality, and it is the responsibility of ESL teachers to make that reality intelligible to the students. In the ideal situation, the teachers would know enough about the students' cultures and personal histories to be able to foresee potential sources of difficulty; a more realistic possibility is an understanding of modern consciousness and the conflicts that are likely to occur when an individual from a less modernized society enters the U.S.

Berger et al. (1973) identify two primary carriers of modernization: technological production and bureaucracy. The influence of these two institutions is so great that there is virtually no aspect of day-to-day existence in a modern society that is free from their impact. It is beyond the scope of this paper to explain in detail the characteristics of technological production or bureaucracy as forces shaping modern consciousness, but it is necessary to sketch the aspects of both which contribute to an overarching world view in modern society. An understanding of the forces which shape 
"modern consciousness" is important if we are to understand and deal with the problems encountered by foreigners in this society. The following description is drawn principally from Berger et al. (1973) especially chapters one, two and four.

\section{Technological production}

1. Rationality. In a modern society, where even the lowly worker acknowledges above him a vast network of science and experts, everything must make sense. There is an explanation for everything. As Goffman (1974) puts it, we can tolerate the unexplained, but not the inexplicable. Members of more traditional societies on the other hand, may define large segments of their experience as being beyond the bounds of human understanding.

2. Componentiality. An artifact of the assembly line, componentiality is the concept that reality is constituted of clearly separable components which relate to each other in structures of causality, time and space. Reality is not conceived as a continuous flow of events and behavior, but rather as a large mosaic of self-contained units which can be brought into relation with other units. Thus, for the modern individual, a particular event is seen to cause or to have been caused by another event; one is not likely to explain events in terms of "God's will." A modern individual is apt to analyze events for their source, and to attempt to see how "things fit together." Reality in less modernized cultures is seen as a whole fabric, rather than as a configuration of smaller patches.

3. Multi-relationality. The average worker in the labor force must cope with an enormous variety of relations-with other people, with material objects, and with abstract entities. This is another constituent element which has been transferred from the realm of technological production to other spheres of social life and consciousness. In our day-to-day existence we must constantly shift roles and relationships to meet the demands placed upon us by a modern society. In less modernized societies, the individual leads a much simpler existence, in which his relationship to people, to the economy and to political forces is perhaps embodied in one or two societal roles.

4. Makeability. Life is viewed as an ongoing problem-solving activity. Unlike the reality of less modernized societies, there are few, if any, spheres in which individuals admit no interference. There are few sacred cows or traditions which exist because "that's the way things are." Modern individuals like to think of life as an 
interaction between people and their environment, in which one strives to perceive, isolate, define and solve problems which occur.

5. Plurality. All human beings recognize the world as consisting of multiple realities. The world of dreams and trances, for example, is perceived as qualitatively different from the reality of everyday life. In modern societies, however, the need to move from one reality to another is greatly intensified. Plurality becomes a basic theme of life. Modern individuals must shift from the world of moon walks, to acupuncture, to Watergate, to unemployment lines, all during the time it takes John Chancellor to read the news. It becomes virtually impossible to establish an overarching symbolic universe because different realities are defined and legitimated in different and often contradictory ways. There is no one explanation which applies to every facet of modern life.

6. Progressivity. Modern society, in direct contrast to traditional cultures, views change of any sort as a positive occurrence. Whereas a less modernized view of the world emphasizes the traditional way of doing things, modern societies thrive on the maxim, "things can always be improved." Berger et al. view this attitude as a manifestation of the "engineering mentality" which tends to maximize the results of any action.

While the above characteristics do not exhaust the ways in which technological production affects the day-to-day lives of people in modernized societies, they do represent important forces of everyday reality which have been borrowed from the world of production lines and time clocks, forces which are not easily understood by individuals from less modernized societies.

\section{Bureaucracy}

In addition to the influences of technological production, the impact of bureaucracy is also felt in society at large. Bureaucracy, the second primary carrier of modern consciousness, occurs as a result of the need to organize people into units which can efficiently realize production goals. Berger et al. (1973) discuss four important themes of bureaucracy for the overarching symbolic universe of modernity.

1. The thematization of society itself. Through most of human history, and even today in traditional cultures, social experience has been defined in terms of "givens", laws or maxims which govern all aspects of reality. Viewed from the perspective of bureaucracy, however, society is experienced as an amorphous reality which has to be organized. Modern individuals are ac- 
customed to viewing social relationships in terms of branching diagrams of responsibility in which everyone assumes certain roles in accomplishing common goals. Society becomes both problematic and manageable. Coupled with makeability, this attitude produces a situation in which change becomes the rule.

2. Adoption of roles as a way of mitigating the threats of modernity. Bureaucracies produce taxonomies of jobs and relationships which determine responsibility for specific tasks. The development of roles and of jurisdictional notions of social responsibility allow people to adopt what Goffman (1961) refers to as role distance; they perform their responsibilities "tongue in cheek," maintaining to themselves and to others that there exists under the mask of the role a more profound individual than can be shown at the moment. This phenomenon undoubtedly occurs in less modernized societies as well, but because reality in traditional cultures is often governed by one overarching symbolic universe, contradictions between role responsibilities are not as great as they are in modernized societies.

3. The cleavage between public and private spheres. As mentioned above, a primary responsibility of bureaucracy is the assignment of jurisdiction. In the modern world, the individual is sharply aware of the dichotomy between the public and private spheres of life. The allocation of certain jurisdictional space to the private sphere allows modern individuals to close themselves off from society in such a way that, at least on the level of consciousness, they must answer to no one. This can cause a crisis of responsibility for people from less modernized societies, where all aspects of life-public and private-are governed largely by the same principles, and society has the right and obligation to evaluate every individual's actions in accordance with those principles. While to a modern individual this might be viewed as an infringement on one's rights it can also be seen as a secure situation in which one always "knows the rules."

4. Human rights as related to bureaucratically identifiable rights. The bureaucratic mentality is perhaps best summed up in the notion of committees and institutions to which are assigned responsibility for virtually every aspect of modern life. Some bureaucracy is always assumed to be responsible for specific human rights, and one should always be able to find someone to complain to if something goes wrong. Gone is the notion of personal responsibility for other people and for the correct way of doing something, both very important aspects of traditional societies (as seen in the effect and effectiveness of extended families.) Along 
with role distance, the notion of identifying human rights with bureaucracies allows people to rationalize their lack of involvement in society or their lack of concern for others.

\section{Conclusion}

Anyone familiar with the problems of setting up life in a strange society can provide numerous anecdotes which illustrate the confusion and frustration which accompany the process of acculturation. For students coming to the U.S. from less modernized cultures, this process involves a major identity crisis. Modernization, which perhaps is proceeding slowly in their country, is thrust upon them with apocalyptic suddenness. However the confrontation manifests itself in individual cases, most students must come to grips with "the essential ordeal of modernization: the collective and individual loss of integrative meanings." (Berger et al. 1973:158)

Undoubtedly, most ESL teachers expend a significant amount of time and effort in helping students adjust to the bewildering pace of American life. For most of us, time so spent is not viewed as a professional responsibility, but rather a gesture of personal kindness. I contend that professional responsibility to our students must extend to include all aspects of their adjustment to the United States. Stevick (1973:101) has made the point that all language learning activities have significance for the "whole person." Even more important, perhaps, is the fact that students' experiences in the "real world" outside our classrooms have significance for their proficiency in the target language. I cite Maslow's (1970) and Howard and Scott's (1965) opinion that the human being is an integrated organism whose successful functioning depends on total mastery of its problems. In other words, individuals must be in a state of total organism health in order to learn:

By total organism health we mean a state in which the organism has achieved mastery over the totality of its environment, so that it uses a minimum of energy and resources for maintenance, allowing a maximum of energy and resources for use in confronting new or recurring problems. To the extent that an organism must utilize its energy and resources for maintenance beyond minimum requirements, thereby limiting its problem-solving capacity, it may be considered as experiencing stress. (Howard and Scot $t$ 1965:152)

I am not advocating an out-patient mental health clinic for every classroom, but rather, as Stevick (1974:384) puts it, "a new 
way of seeing." I believe that second language classes involve a content as well as a skill; we must attempt to convey the context as well as the language. But this cannot be achieved in anecdotal fashion. As enlightening or amusing as they might be, anecdotes do not allow students to generalize to their own experiences.

The phenomenological analysis of second language learning presented above provides a broad theoretical foundation within which we can attempt to explain social phenomena to our students. The essential first step in "curing" culture shock is to make explicit all of those presuppositions which form the fabric of modern consciousness. Once our students recognize the subjective, socially constructed nature of reality, they will be in a much better position to understand the target language and culture.

\section{REFERENCES}

Bateson, G. 1972. Steps to an Ecology of Mind. New York: Ballentine Books. Berger, P. L., and Luckmann, T. 1967. The Social Construction of Reality. New York: Anchor Books.

Berger, P. L., Berger, B. and Kellner, H. 1973. The Homeless Mind. New York: Vintage Books.

Brown, H. D. 1975. The next 25 years: shaping the revolution. In H. Dulay and M. Burt (eds.). New Directions in Second Language Learning, Teaching and Bilingual Education, 80-85. Washington, D.C.: TESOL.

Gardner, R. C. and Lambert, W. E. 1972. Attitudes and Motivation in Second Language Learning. Rowley, Mass.: Newbury House.

Gardner, R. C. and Lambert, W. E. 1973. Attitudes and motivation: their role in second language acquisition. In Oller, J. W. and Richards, J. C. (Eds.) Focus on the Learner, 235-245. Rowley, Mass.: Newbury House.

Goffman, E. 1974. Frame Analysis. New York: Colophon Books.

Grittner, F. 1973. Barbarians, bandwagons and foreign language scholarship. Modern Language Journal 57.241-248.

Guiora, A. Z., Brannon, R. C. L., Dull, C. Y. 1972. Empathy and second language learning. Language Learning 22.111-138.

Guiora, A. Z., Paluszny, M., Beit Hallahim, B., Catford, J. C., Cooley, R., and Dull, C. Y. 1975. Language and person: studies in language behavior. Language Learning 25.43-62.

Howard, A. and Scott, R. A. 1965. A proposed framework for the analysis of stress in the human organism. Behavioral Science 10.141-160.

Laing, R. D. 1967. The Politics of Experience. London: Penguin.

Maslow, A. H. 1970. Motivation and Personality (2nd Edition). New York: Harper and Row.

Mead, G. H. 1964. On Social Psychology. Chicago: University of Chicago Press.

Oberg, K. 1960. Culture shock: adjustment to new cultural environments. Practical Anthropologist 7.177-182.

Schumann, J. H. 1976. Social distance as a factor in second language acquisition. Language Learning 26.135-144.

Stengel, E. 1939. On learning a new language. International Journal of Psychoanalysis 20.471-479. 
Stevick, E. W. 1973. Before linguistics and beneath method. Georgetown University Round Table, 99-106. Georgetown University.

Stevick, E. W. 1974. Language teaching must do an about-face. Modern Language Journal 58.379-383.

Taylor, B. P. 1973. Review of Gardner and Lambert, Attitudes and Motivation in Second Language Learning. Language Learning 23.145-149. 